\title{
Relationship of serum testosterone with coronary artery disease in young adult males of Bangladesh
}

\author{
Amit Kumar Pramanik, Mohammad Monzurul Alam Bhuiyan, Mst Shaila Yesmin, Sheuli Ferdousi, \\ Tanjima Parvin, Kajal Kumar Karmoker, Saifun Nahar, Joydeep Goswami, Debatosh Paul
}

\begin{abstract}
Article Info
Department of Transfusion Medicine, Rajshahi Medical College Hospital, Rajshahi, Bangladesh (AKP); Department of Laboratory Medicine, BSMMU, Dhaka, Bangladesh (MMAB, MSY, SF, DP); Department of Cardiology, BSMMU, Dhaka, Bangladesh (TP); Department of Cardiology, National Institute of Traumatology and Orthopedic Rehabilitation, Dhaka, Bangladesh (KKK); Department of Laboratory Medicine, Ahsania Mission Cancer and General Hospital, Dhaka, Bangladesh (SN); Department of Psychiatry, National Institute of Mental Health and Hospital, Dhaka, Bangladesh (JG).

For Correspondence:

Amit Kumar Pramanik,

E-mail: amit34th@gmail.com,

Received:

Accepted:

29 October 2020

Available Online: $\quad 30$ November 2021
\end{abstract}

ISSN: 2224-7750 (Online) 2074-2908 (Print)

DOI: https://doi.org/10.3329/bsmmuj.v14i3.56601

Keywords: Coronary artery disease, total testosterone, Gensini score.

Cite this article:

Pramanik AK, Bhuiyan MMA, Yesmin MS, Ferdousi S, Parvin T, Karmoker KK, Nahar S, Goswami J, Paul D. Relationship of serum testosterone with coronary artery disease in young adult males of Bangladesh. Bangabandhu Sheikh Mujib Med Univ J. 2021; 14(3): 67-73.

\section{Copyright:}

The copyright of this article is retained by the author(s) [Atribution CC-By 4.0]

\section{Available at:}

www.banglajol.info

A Journal of Bangabandhu Sheikh Mujib Medical University, Dhaka, Bangladesh

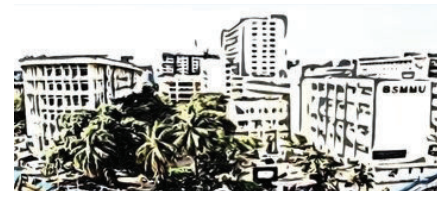

\section{Abstract}

The incidence rate and mortality of coronary artery disease is obviously higher in men than in women, which may be related to the influence of serum testosterone. This cross-sectional study was conducted at Department of Laboratory Medicine in collaboration with Department of Cardiology, BSMMU and National Institute of Cardiovascular Diseases (NICVD), Dhaka from March 2020 to February 2021 to investigate the association of serum testosterone with coronary artery disease in young adult males in Bangladesh. Total 110 subjects from inpatient Department of Cardiology were enrolled, 60 were CAD patients and 50 were Normal Coronaries according to coronary angiography report. In this study, 60 patients with coronary artery disease were compared with 50 normal coronary subjects. Mean age in CAD group and normal coronaries was $37.72 \pm 2.73$ and $37.48 \pm 2.54$ years respectively. Hypertension, diabetes mellitus and dyslipidemia were significantly higher in CAD group. Total testosterone levels of CAD were significantly lower than those of normal coronaries $(2.11 \pm 0.81 \mathrm{ng} / \mathrm{ml}$ vs $2.94 \pm 0.78 \mathrm{ng} / \mathrm{ml})$. Among 60 CAD patients, 10 patients had single vessel disease, 17 patients had double vessel disease and 33 patients had triple vessel disease. There was significant association between the level of total testosterone and the number of affected vessels within CAD group ( $p=0.1$. This study also showed that total testosterone level was negatively correlated with Gensini score. Serum total testosterone was significantly lower in patients with CAD compared to normal coronaries. Patients with lower total testosterone levels had higher Gensini score. Low level of total testosterone may be related to the development of coronary artery disease.

\section{Introduction}

Cardiovascular diseases (CVD) are the leading cause of death world wide and coronary artery disease $(\mathrm{CAD})$ is the most common to this mortality. ${ }^{1}$ The prevalence of CAD is high among South Asians. Prevalence estimates over the last thirty years range from $7.6 \%$ to $11 \%{ }^{2}$ The exact prevalence of CAD in Bangladesh isn't known. More recent data indicates CAD prevalence between $1.85 \%$ to $3.4 \%$ in rural and $19.6 \%$ in urban population of Bangladesh. ${ }^{3}$ Coronary artery disease (CAD) occurs more frequently in men than in women. Despite various hypo- theses, the rationale for this phenomenon remains unknown. ${ }^{4}$ However, androgens are thought to be responsible for the higher prevalence of CAD in men. The difference may result from the negative influence of androgens and positive influence of estrogens on the lipid profile. ${ }^{5}$ Sex hormones have shown to regulate lipoprotein metabolism and seems to influence the development of CAD. ${ }^{6}$ In the last couple of decades, there has been an emergence of several non-traditional risk factors which are associated with an inflammatory and pro-coagulant states in patients with CAD. ${ }^{7}$ Studies shown that hypogonadal males have an increased prevalence of the traditional coronary risk factors and CAD. ${ }^{8-9}$ Furthermore, androgen replace- ment therapy has been shown to improve risk factor and symptoms of ischemia in hypogonadal 
males. ${ }^{10-12}$ Phillips et al. was the first to report an inverse correlation between angio- graphically proven CAD and testosterone levels. ${ }^{13}$ During male aging, serum testosterone level declines gradually ${ }^{14}$, while the risk of cardiovascular and thrombotic events begins to increase. ${ }^{15}$ Since the aging process commences after puberty, it can be presumed that the decline in testosterone level starts at a younger age than is generally expected. Thus, young adult male patients with acquired cardiovascular conditions, particularly CAD, may have a lower level of testosterone. In this context, this study aims to evaluate the relationship between testosterone and coronary artery diseases in young males.

\section{Methods}

This cross-sectional study was conducted at Department of Laboratory Medicine in collaboration with Department of Cardiology, Bangabandhu Sheikh Mujib Medical University (BSMMU) and National Institute of Cardiovascular Diseases (NICVD), Dhaka from March 2020 to February 2021. Total 110 subjects from inpatient Department of Cardiology were enrolled, 60 were CAD patients and 50 were patients with normal coronaries according to the coronary angiography findings. Young adult male (18-40 years) patients presented with acute coronary syndrome admitted into coronary care unit (CCU) at BSMMU and NICVD were included in this study. The exclusion criteria included history of known case of $\mathrm{CAD}$ or myocardial infarction, renal failure, hepatic failure, respiratory failure, testosterone therapy, malignancy, presence of acute illness, use of medications that affect sexual hormones, such as anticonvulsants and antithyroid drugs, valvular and congenital heart disease, cardiomegaly, previous history of angioplasty, major trauma or surgery within 3 months. After selection, all the patients were thoroughly informed about the aims, objectives and procedure of the study and were encouraged for their voluntary participation. Informed written consent was taken from each subject. A detail personal, medical, occupational, educational and smoking history were recorded in a preformed data sheet and thorough physical examinations were done and documented. Physiological measurements were recorded at baseline for all participants. After an overnight fasting venous blood samples were obtained on the day of the coronary angiography in order to measure serum biochemistry. Investigations were done in Department of Laboratory Medicine, BSMMU. Serum total testosterone level was assessed from stored separated serum by enzyme-linked immunosorbent assay (ELISA). Collected blood samples were run in each successive day for serum lipid profile and fasting plasma glucose. The serum lipid profile and fasting plasma glucose were assessed by automated biochemistry analyzer SIEMENS Dimension EXL with LM by the principle of photometric. The presence of CAD was confirmed by conventional angiography and analyzed for presence, extent and severity of CAD. In coronary angiogram, stenosis $\geq 50 \%$ in left main coronary artery or stenosis $\geq 70 \%$ in any epicardial coronary artery were considered as CAD group. Patients with stenosis $<50 \%$ in left main coronary artery or stenosis $<70 \%$ in any epicardial coronary artery were considered as non-CAD group. Severity of CAD was expressed by Gensini score. ${ }^{16}$ Gensini score was calculated in CAD group. The angiography was performed in the cath-lab under local anesthesia by an expert cardiologist. Statistical analysis were carried out by using the Statistical Package for Social Sciences version 23.0. The mean values were calculated for continuous variables. ANOVA test was used to compare the groups based on vessels score and Spearman's correlation co-efficient test was done to assess the relationship between total testosterone and Gensini Score.

\section{Result}

Out of total 110 subjects, 60 patients with coronary artery disease were compared with 50 normal coronary subjects. Baseline and clinical characteristics of CAD group and normal coronaries group are displayed in Table-I. The age of both group ranged from 30-40 years. Mean ages of the two groups were $37.72 \pm 2.73$ years vs $37.48 \pm 2.54$ years which was not significantly different $(p=0.64)$. Mean BMI of the two groups were $25.74 \pm 2.68$ vs $25.66 \pm 2$.90. It was also not significantly different $(p=0.50)$. Mean systolic blood pressure, diastolic blood pressure and pulse were higher in CAD group compared to normal coronaries but not significantly different $(\mathrm{p}>0.05)$. Prevalence of traditional risk factors such as smoking, hypertension, diabetes mellitus, family history of $\mathrm{CAD}$ and dyslipidemia were more prevalent in CAD group than normal coronaries group. Among the studied subjects, smoker was higher in CAD than normal coronaries (75\% vs. $60 \%$ ) with no significant difference $(p=0.093)$. Hypertension was higher in CAD than normal coronaries ( $80 \%$ vs. $56 \%$ ) with significant difference $(p=0.008)$. Diabetes mellitus was also more in CAD than normal coronaries $(61.67 \%$ vs. $26 \%)$ with significant difference $(p=0.001)$. Family history of CAD was more in CAD than normal coronaries $(60 \%$ vs. 52\%) with no significant difference $(p=0.557)$. Dyslipidemia was higher in CAD than normal coronaries $(86.66 \%$ vs. $58 \%)$ with statistically significant difference $(p=0.001)$ (Table-I). 
Table-I

Baseline and clinical characteristics of the study population $(\mathbf{N}=110)$.

\begin{tabular}{|l|c|c|c|}
\hline Variables & CAD $(\mathrm{n}=60)$ & Normal Coronaries $(\mathrm{n}=50)$ & $\mathrm{p}$ value \\
\hline Age (year) & $37.72 \pm 2.73$ & $37.48 \pm 2.54$ & 0.64 \\
\hline BMI & $25.74 \pm 2.68$ & $25.66 \pm 2.90$ & 0.50 \\
\hline Systolic BP $(\mathrm{mmHg})$ & $138.58 \pm 25.59$ & $133.60 \pm 16.22$ & 0.236 \\
\hline Diastolic BP $(\mathrm{mmHg})$ & $86.5 \pm 12.63$ & $85.4 \pm 12.64$ & 0.650 \\
\hline Pulse $(/ \mathrm{min})$ & $80.35 \pm 9.93$ & $77.83 \pm 9.63$ & 0.093 \\
\hline Smoking(\%) & $45(75 \%)$ & $30(60 \%)$ & $0.008 \mathrm{~s}$ \\
\hline Hypertension(\%) & $48(80 \%)$ & $28(56 \%)$ & $0.001 \mathrm{~s}$ \\
\hline Diabetes mellitus(\%) & $37(61.67 \%)$ & $13(26 \%)$ & 0.527 \\
\hline Family History of CAD(\%) & $36(60 \%)$ & $26(52 \%)$ & $0.001 \mathrm{~s}$ \\
\hline Dyslipidemia(\%) & $52(86.66 \%)$ & $29(58 \%)$ & \\
\hline
\end{tabular}

p-value $<0.05$ was significant, Data were presented as mean \pm SD for continuous variables, $s=$ significant, $B M I=B o d y$ mass index, $\mathrm{BP}=\mathrm{Blood}$ pressure, $\mathrm{CAD}=$ Coronary artery disease.

The mean value of HDL and triglyceride was significantly different between two groups $(\mathrm{p}<0.05)$. The mean HDL was $32.25 \pm 5.02 \mathrm{mg} / \mathrm{dl}$ in CAD and $35.78 \pm 5.84 \mathrm{mg} / \mathrm{dl}$ in normal coronaries group with statistically significant difference $(p=0.001)$. The mean triglyceride was a $212.22 \pm 116.8 \mathrm{mg} / \mathrm{dl}$ in CAD and $160.86 \pm 96.65 \mathrm{mg} / \mathrm{dl}$ in normal coronaries with significant difference $(\mathrm{p}=0.013)$. Mean total cholesterol and LDL were not significantly higher in CAD than normal coronaries $(p>0.05)$. The mean value of fasting blood sugar (FBS) were higher in CAD group than normal coronaries but not statistically significant $(7.29 \pm 1.95$ vs $6.71 \pm 2.08 \mathrm{mmol} / \mathrm{l}, \mathrm{p}>0.05)$. The mean value of serum total testosterone $(\mathrm{ng} / \mathrm{ml})$ were significantly lower in patients with CAD than normal coronaries group ( $2.11 \pm 0.81$ vs $2.94 \pm 0.78 \mathrm{ng} / \mathrm{ml}, \mathrm{p}=0.01$ ) (Table-II).

Table-II

The results of laboratory values of the study population $(N=110)$.

\begin{tabular}{|l|c|c|c|}
\hline Variables & CAD $(\mathrm{n}=60)$ & Normal Coronaries $(\mathrm{n}=50)$ & $\mathrm{p}$ value \\
\hline Total Cholesterol $(\mathrm{mg} / \mathrm{dl})$ & $185.95 \pm 51.35$ & $177.98 \pm 42.67$ & 0.375 \\
\hline HDL $(\mathrm{mg} / \mathrm{dl})$ & $32.25 \pm 5.02$ & $35.78 \pm 5.84$ & $0.001 \mathrm{~s}$ \\
\hline LDL $(\mathrm{mg} / \mathrm{dl})$ & $110.56 \pm 43.38$ & $108.36 \pm 32.39$ & 0.762 \\
\hline Triglyceride $(\mathrm{mg} / \mathrm{dl})$ & $212.22 \pm 116.8$ & $160.86 \pm 96.65$ & 0.131 \\
\hline FBS $(\mathrm{mmol} / \mathrm{L})$ & $7.29 \pm 1.95$ & $6.71 \pm 2.08$ & $0.01 \mathrm{~s}$ \\
\hline Serum Total Testosterone $(\mathrm{ng} / \mathrm{ml})$ & $2.11 \pm 0.81$ & $2.94 \pm 0.78$ & \\
\hline
\end{tabular}

p-value $<0.05$ was significant, Data were presented as mean \pm SD for continuous variables, $s=$ significant, $C A D=C$ Coronary artery disease, HDL=High density lipoprotein, LDL=Low density lipoprotein, FBS= Fasting blood sugar. 
Table-III

Comparison of Gensini score and total testosterone level with type of vessel disease in CAD (N=60)

\begin{tabular}{|l|c|c|c|c|}
\hline Type of Vessel Disease & Single $(\mathrm{n}=10)$ & Double $(\mathrm{n}=17)$ & Triple $(\mathrm{n}=33)$ & $\mathrm{p}$-value \\
\hline Gensini score $($ Mean \pm SD) & $20.70 \pm 14.14$ & $40.67 \pm 25.13$ & $56.06 \pm 23.80$ & $0.001 \mathrm{~s}$ \\
\hline Total testosterone $(\mathrm{ng} / \mathrm{ml})($ Mean \pm SD) & $2.91 \pm 0.82$ & $2.35 \pm 0.99$ & $1.75 \pm 0.40$ & $0.01 \mathrm{~s}$ \\
\hline
\end{tabular}

ANOVA test was done, s=Significant, Data were expressed as mean \pm SD.

In this study, among 60 CAD patients, 10 patients had single vessel disease, 17 patients had double vessel disease and 33 patients had triple vessel disease. The results of the comparison between the Gensini score and total testosterone within CAD group based on the number of affected vessels are summarized in Table-III. There was a significant association between the level of total testosterone and the number of affected vessels within CAD group. Patients with triple vessel disease had lower level of total testosterone compared to those with double and single vessel disease $(p<0.05)$. The mean Gensini score was higher in patients with triple vessel disease compared to those with double and single vessel disease. There were a significant increasing trend in the number of subjects with low serum total testosterone level based on the vessel score and degree of involvement (Table-III, Figure-1).

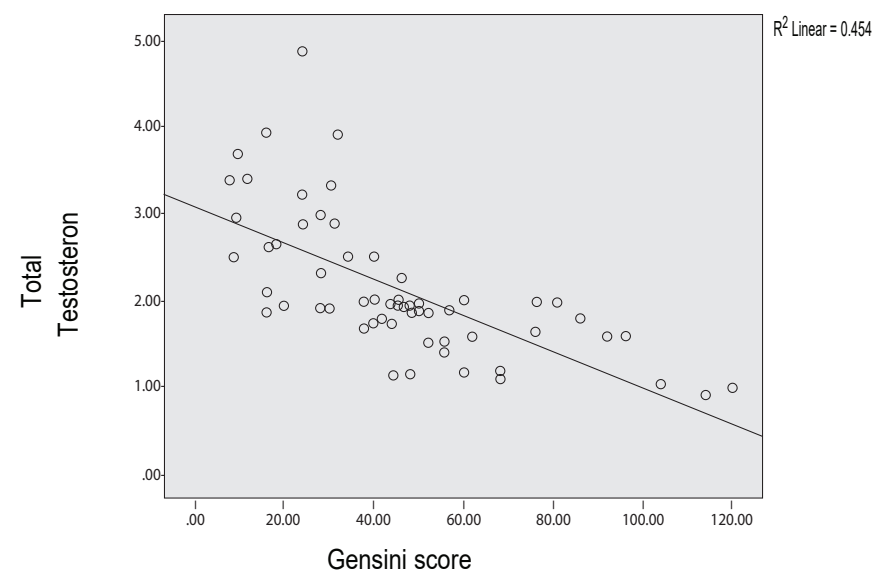

Figure-1: Scatter diagram showing a negative correlation between serum total testosterone levels and Gensini scores in CAD ( $\mathrm{r}=-0.759, \mathrm{p}=0.01)$.

\section{Discussion}

This cross-sectional study was conducted at Department of Laboratory Medicine in collaboration with Department of Cardiology, Bangabandhu Sheikh Mujib Medical University (BSMMU) and National Institute of Cardiovascular Diseases (NICVD), Dhaka from March 2020 to February 2021. A total of
110 patients were included in this study dividing into two groups as patients with CAD (60 patients) and patients with normal coronaries (50 patients).

In this study, it was observed that mean age of CAD was found $37.72 \pm 2.73$ years and $37.48 \pm 2.54$ years in normal coronaries. The differences of mean age between the two groups were not statistically significant $(\mathrm{p}=0.64)$. Turhan et al. found that mean age of CAD was $41.0 \pm 4.7$ years and $41.3 \pm 3.8$ years in control with no statistically significant difference $(p=0.698)$ which was consistent with present study. ${ }^{17}$

The current study demonstrates that baseline risk factors had an important role in identifying young male patients at risk for CAD. Prevalence of traditional risk factors such as smoking, hypertension, diabetes mellitus, family history of CAD and dyslipidemia were more prevalent in CAD than normal coronaries group. Among them, hypertension, diabetes mellitus and dyslipidemia were significantly higher $(p<0.05)$ but smoking and family history of CAD were not significantly higher $(\mathrm{p}>0.05)$ in CAD group.

Although BMI was not significantly difference between two groups $(\mathrm{p}>0.05)$. Turhan et al reported that prevalence of diabetes mellitus, smoking, hyperlipidemia and family history of CAD were significantly higher $(p<0.05)$ in CAD group than normal coronary. Hypertension and BMI were higher in CAD group than those with normal coronary arteries but it was not found statistically significant in their study. ${ }^{17}$ Alkamel et al found that prevalence of diabetes mellitus and hyperlipidemia was significantly higher in CAD group than those with normal coronary arteries. Other risk factors like smoking, hypertension and family history of CAD also higher in CAD group than normal coronary but not statistically significant $(p>0.05)$ in their study. BMI was also not significantly different between two groups in their study $(p>0.05) .19$

In the present study, we found that serum total testosterone concentration was significantly lower in patients with coronary artery disease compared to the normal coronaries. 
This finding is consistent with the previous studies suggesting that low testosterone may be a risk factor for the development of CAD. ${ }^{17-19}$ These findings may be explained by the effect of either total testosterone on lipid profile or testosterone may be itself alone affect on atherosclerosis for CAD. Our study also demonstrated statistically significant negative correlation between total testosterone levels and severity of CAD; this result was consistent with previous studies $^{18-21}$. Previously some studies demonstrated that a low testosterone level is associated with markers of atherosclerosis such as impaired endothelial vasomotor function, increased carotid intima-media thickness and aortic calcification. $^{22-24}$ These results suggested that serum low testosterone level may be involved in the pathogenesis of CAD. Webb et al. showed that exogenous testosterone could induce coronary artery dilatation and increases coronary blood flow in men with established CAD. ${ }^{25}$ Mathur et al. further found that long-term testosterone replacement therapy could decrease angina threshold and encourage plaque stability in men. ${ }^{26}$ These results suggested that serum low testosterone level may be involved in the pathogenesis of $\mathrm{CAD}$ and exogenous testosterone replacement therapy may be a potential therapeutic approach for CAD. However, raising endogenous testosterone level with gonadotropins remains to be explored, which may be another option for therapeutic approach for CAD. Although the effects of testosterone could partially explain the difference in the CAD prevalence between the two sexes, there is no definite evidence available for increased incidence of myocardial infarction and CAD by testosterone. Moreover, there are data suggesting that testosterone in fact may have protective

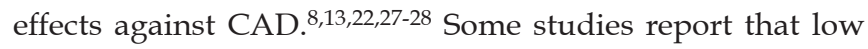
dose testosterone therapy in men with CAD reverses exercise-induced myocardial ischemia and intravenous testosterone administration has anti-ischemic effects. ${ }^{12,29-30}$ Intracoronary administration of physiologic concentrations of testosterone was shown to enhance coronary blood flow by dilating the coronary arteries in patients with CAD and cause vasodilation in both coronary and systemic arteries of animal models in vitro. ${ }^{25,31}$ This vasodilation could be attributed to increased endothelial nitric oxide release. ${ }^{32}$ These findings when considered together with the decreased levels of testosterone by advancing age may suggest that the decrease in plasma testosterone concentrations may be one of the factors contributing to increased incidence of CAD by increasing age. ${ }^{33}$ Current study also found that total testosterone were significantly associated with the number of affected coronary vessels and Gensini score which was consistent with previous study done by Alkamel et al. ${ }^{19}$ Exact mechanisms linking low testosterone with CAD have not been fully elucidated, and are likely to involve complex interconnected processes including accelerated atherosclerosis, abnormal activation of inflammatory response, impaired vasomotion and endothelial dysfunction. Additional investigations are required to further clarify the relationship between serum low testosterone levels and CAD.

\section{Study Limitation}

The study had some limitations. Firstly, cross-sectional design of this study made it impossible to investigate whether CAD preceded or followed the decline in serum testosterone level. The study population was selected from only two tertiary level hospitals in Dhaka city. Therefore, sample may not be representative of the selected population of the country. Patients with exclusion criteria were excluded on the basis of history and clinical feature. No confirmatory tests were carried out to exclude these patients due to lack of financial source and time constraint.

\section{Conclusion}

Lower level of serum testosterone was observed in the young adult males with CAD than in normal coronary subjects. Lower levels of testosterone were significantly correlated with higher number of affected vessels and higher Gensini score. Based on these results, serum testosterone may be used as a predictive tool for the risk of CAD in young adult males.

\section{Acknowledgement}

Authors of this study are thankful to the authority of the Department of Cardiology, BSMMU and NICVD and Department of Laboratory Medicine, BSMMU, for their nice cooperation during sample collection, laboratory procedure and also thankful to the study subjects for their active and enthusiastic participation.

Funding : Self-funded.

\section{Ethical consideration}

The protocol for this study was approved by the Institutional Review Board of Bangabandhu Sheikh Mujib Medical University. 


\section{Conflicts of interest}

Authors declare no conflict of interest.

\section{References}

1. Murray CJ, Lopez AD. Mortality by cause for eight regions of the world: Global Burden of Disease Study. The lancet. 1997; 349(9061):1269-76.

2. Gupta M, Singh N, Verma S. South Asians and cardiovascular risk: what clinicians should know. Circulation. 2006;113(25):e924-9.

3. Islam AM, Majumder AA. Coronary artery disease in Bangladesh: A review. IHJ. 2013; 65(4): 424-35.

4. BHF statistics database, 2010. Available at: http://www.bhf.org.uk/research/heart-statistics.aspx [Accesessed on 2020 Dec 1].

5. Anderson KM, Castelli WP, Levy D. Cholesterol and mortality: 30 years of follow-up from the Framingham Study. Jama. 1987;257(16):2176-80.

6. Nathan L, Shi W, Dinh H, Mukherjee TK, Wang X, Lusis AJ et al. Testosterone inhibits early atherogenesis by conversion to estradiol: critical role of aromatase. Proceedings of the National Academy of Sciences. 2001;98(6):3589-93.

7. Balagopal P, De Ferranti SD, Cook S, Daniels SR, Gidding SS, Hayman LL et al. Nontraditional risk factors and biomarkers for cardiovascular disease: mechanistic, research, and clinical considerations for youth: a scientific statement from the American Heart Association. Circulation. 2011;123(23):2749-69.

8. English KM, Mandour O, Steeds RP, Diver MJ, Jones TH, Channer KS. Men with coronary artery disease have lower levels of androgens than men with normal coronary angiograms. European heart journal. 2000;21(11):890-4.

9. Shores MM, Matsumoto AM, Sloan KL, Kivlahan DR. Low serum testosterone and mortality in male veterans. Archives of internal medicine. 2006 ;166(15):1660-5.

10. Heufelder AE, Saad F, Bunck MC, Gooren L. Fifty-two-week treatment with diet and exercise plus transdermal testosterone reverses the metabolic syndrome and improves glycemic control in men with newly diagnosed type 2 diabetes and subnormal plasma testosterone. Journal of andrology. 2009 ;30(6):726-33.

11. Traish AM, Haider A, Doros G, Saad F. Long-term testosterone therapy in hypogonadal men ameliorates elements of the metabolic syndrome: an observational, long-term registry study. International journal of clinical practice. 2014;68(3):314-29.
12. English KM, Steeds RP, Jones TH, Diver MJ, Channer KS. Low-dose transdermal testosterone therapy improves angina threshold in men with chronic stable angina: a randomized, double-blind, placebo-controlled study. Circulation. 2000 ;102(16):1906-11.

13. Phillips GB, Pinkernell BH, Jing TY. The association of hypotestosteronemia with coronary artery disease in men. Arteriosclerosis and thrombosis: a journal of vascular biology. 1994 ;14(5):701-6.

14. Yeap BB. Testosterone and ill health in aging men. Nature clinical practice endocrinology \& metabolism. 2009;5(2) :113-21.

15. North BJ, Sinclair DA. The intersection between aging and cardiovascular disease. Circulation research. 2012 Apr 13;110(8):1097-108.

16. Gensini GG. A more meaningful scoring system for determining the severity of coronary heart disease. Am J cardiol. 1983;51:606.

17. Turhan S, Tulunay C, Güleç S, Özdöl Ç, Kilickap M, Altn T et al. The association between androgen levels and premature coronary artery disease in men. Coronary artery disease. 2007 ;18(3):159-62.

18. Gururani K, Jose J, George PV. Testosterone as a marker of coronary artery disease severity in middle aged males. Indian heart journal. $2016 ; 68: S 16-20$.

19. Alkamel A, Shafiee A, Jalali A, Boroumand M, Nozari Y. The association between premature coronary artery disease and level of testosterone in young adult males. Archives of Iranian medicine. 2014 ;17(8):545-550.

20. Li L, Guo CY, Jia EZ, Zhu TB, Wang LS. Testosterone is negatively associated with severity of coronary atherosclerosis in men. Asian journal of andrology. 2012 ;14(6):875-878.

21. Rosano GM, Sheiban I, Massaro R, Pagnotta P, Marazzi G, Vitale $C$ et al. Low testosterone levels are associated with coronary artery disease in male patients with angina. International Journal of Impotence Research. 2007;19(2):176-82.

22. Hak AE, Witteman JC, de Jong FH, Geerlings MI, Hofman A, Pols HA. Low levels of endogenous androgens increase the risk of atherosclerosis in elderly men: the Rotterdam study. The Journal of Clinical Endocrinology \& Metabolism. 2002;87(8):3632-9.

23. Van den Beld AW, Bots ML, Janssen JA, Pols HA, Lamberts SW, Grobbee DE. Endogenous hormones and carotid atherosclerosis in elderly men. American journal of epidemiology. 2003 ;157(1):25-31. 
24. Akishita M, Hashimoto M, Ohike Y, Ogawa S, Iijima K, Eto $\mathrm{M}$ et al. Low testosterone level is an independent determinant of endothelial dysfunction in men. Hypertension research. 2007 ;30(11):1029-34.

25. Webb CM, McNeill JG, Hayward CS, De Zeigler D, Collins P. Effects of testosterone on coronary vasomotor regulation in men with coronary heart disease. Circulation. $1999 ; 100(16): 1690-6$.

26. Mathur A, Malkin C, Saeed B, Muthusamy R, Jones TH, Channer $K$. Long-term benefits of testosterone replacement therapy on angina threshold and atheroma in men. European Journal of Endocrinology. 2009;161(3):443-9.

27. Alexandersen P, Haarbo J, Byrjalsen I, Lawaetz H, Christiansen C. Natural androgens inhibit male atherosclerosis: a study in castrated, cholesterol-fed rabbits. Circulation Research. 1999;84(7):813-9.

28. Chute CG, Baron JA, Plymate SR, Kiel DP, Pavia AT et al. Sex hormones and coronary artery disease. The Journal of Urology. 1988;139(3):661-2.
29. Rosano GM, Leonardo F, Pagnotta P, Pelliccia F, Panina G, Cerquetani $\mathrm{E}$ et al. Acute anti-ischemic effect of testosterone in men with coronary artery disease. Circulation. 1999 ;99 (13):1666-70.

30. Webb CM, Adamson DL, de Zeigler D, Collins P. Effect of acute testosterone on myocardial ischemia in men with coronary artery disease. American Journal of Cardiology. 1999;83(3):437-9.

31. Yue P, Chatterjee K, Beale C, Poole-Wilson PA, Collins P. Testosterone relaxes rabbit coronary arteries and aorta. Circulation. 1995 15;91(4):1154-60.

32. Costarella CE, Stallone JN, Rutecki GW, Whittier FC. Testosterone causes direct relaxation of rat thoracic aorta. Journal of Pharmacology and Experimental Therapeutics. 1996 ;277(1):34-9.

33. Channer KS, Jones TH. Cardiovascular effects of testosterone: implications of the 'male menopause'? Heart. 2003; 89(2):121-2. 